\title{
Similes on the Internet have explanations
}

\author{
CARLOS RONCERO, JOHN M. KENNEDY, and RON SMYTH \\ University of Toronto at Scarborough, Toronto, Ontario, Canada
}

\begin{abstract}
We searched the Internet for expressions linking topics, such as crime, and vehicles, such as disease, as similes (crime is like a disease) and as metaphors (crime is a disease). We counted the number of times the expressions were accompanied by explanations (crime is like a disease because it spreads by direct personal influence). Similes were more likely than metaphors to be accompanied by explanations. Similes may be preferred if a writer wants to express an out-of-the-ordinary relation between the topic and the vehicle.
\end{abstract}

Here, we will test a hypothesis about metaphors, similes, and explanations, using sentences on the Internet.

A simile is a figurative comparison that includes the word like (or as), such as highways are like snakes. A metaphor is a figurative comparison without the term like, as in crime is a disease. Similes imitate literal comparisons, such as Fords are like Chryslers. Metaphors make claims about a category, as in Fords are cars (Gentner \& Bowdle, 2001; Glucksberg, 2001). Comparisons and categorization are vital to human cognition, so figurative expressions of them could be present in all cultures, but although it has been studied for millennia, the connection between similes and metaphors is still much debated (Chiappe \& Kennedy, 1999).

A figurative relation usually can be expressed as either a metaphor or a simile using the same word pairs. Crime is like a disease, without the word like, has the same sense as crime is a disease. Literal comparisons cannot drop or add like with impunity. Fords are like cars is incorrect.

Chiappe, Kennedy, and Smykowski (2003) have argued that metaphors are preferred when the relationship being expressed is quite apt, as in cigarettes are time bombs, but that similes are preferred if not, as in trees are like straws. Aptness is high if the vehicle (time bombs) points out what the reader takes to be significant features of the topic (cigarettes).

Of interest for the present purposes, Chiappe, Kennedy, and Chiappe (2003) found that aptness ratings correlated strongly with ease of comprehension. This suggests that metaphors would be used if a statement was easily comprehended, and similes would be used, if not. Similes are more challenging. Here we take up an intriguing implication of this argument. If writers thought comprehension were impeded, what would ensue? In everyday practice, writers might add explanations to their expressions. That is, if a simile did indeed seem unlikely to convey a key

Correspondence concerning this article should be sent to J. M. Kennedy, Department of Life Sciences-Psychology, University of Toronto at Scarborough, 1265 Military Trail, Toronto, ON, M1C1A4, Canada (e-mail: kennedy@utsc.utoronto.ca). idea, the writer should expose its rationale to the light of day, as in trees are like straws in the way they suck up water and nutrients. If they readily bring to mind what the writer wants the expression to specify, metaphors could often occur baldly, totally without explanation, as in life is a journey, as compared with life is like a box of chocolates-you never know what you are going to get.

To check whether, when compared with metaphors, similes are used more often with explanations, we turned to a very large corpus of sentences. We used Google to search the Internet for metaphors and similes. We examined the products for accompanying explanations.

\section{EXPERIMENT 1}

\section{Method}

A set of 52 pairs of terms was selected from Chiappe, Kennedy, and Chiappe (2003); for example, rage was paired with volcano, and education with stairway. The pairs were written as sentences in metaphor form (rage is a volcano) and simile form (rage is like a volcano).

Each sentence was entered into a search engine, and an Internet search was undertaken to discover the frequency of each sentence.

The sentences were sought via Google. When a sentence is written in quotation marks in the search box, Google returns a list of Web sites that contain each sentence and shows the linguistic context. When life is a journey was entered into the search box, Google produced a list of Web sites containing life is a journey as well as words adjacent to the sentence at each Web site. A count of the Web sites constitutes the frequency measure for that sentence. The order in which Google presents Web sites is determined by the number of links to that page by pages that have many links.

To ensure that the count included only relevant productions of metaphors and similes, constraints were used, as follows:

\section{Constraints for the Target Sentences}

Constraint 1: The principle of 1 Web site $=1$ production Productions listed within the same Web site were recorded as a single production. Thus, no single Web site could dominate the recorded frequency.

Constraint 2: The "no example" principle. Productions that were examples of figurative claims were excluded. For example, a Web site would not be counted if it included the sentence "The metaphor 'life is a journey' can be rewritten as the simile 'life is like a journey." For this reason, productions from psychology articles, Web sites, and academic discussions of figurative language were not included. 
Constraint 3: The "identical syntax" principle. A production may have used the same word order as the search sentence, but it was not counted if it was not syntactically the same sentence. For example:

\section{Target sentence: Wisdom is like an ocean. \\ Found sentence: The person who doubts he will receive wis- dom is like an ocean wave that is driven and tossed.}

Constraint 4: The principle of unclear context. The production was not used if it could not be determined whether it was a use of figurative language or an example of figurative language (as defined in Constraint 2).

Constraint 5: The principle of 1 referent $=1$ production. Productions with the same referent were recorded as a single production. For example, several Web sites could include the book title Wisdom Is an Ocean, but each refers to the same token.

Constraint 6: The principle of 1 context $=1$ production. Metaphors and similes repeated with the same linguistic context were recorded as a single production. By this rule, all instances of the mind is an umbrella - best when open should be recorded as a single production. This prevents a few uses of an expression from dominating the results.

Constraint 7: The principle of different semantics. Productions may match the target sentence in word order, but have a different meaning. For example,

$$
\begin{array}{ll}
\text { Target sentence: } & \text { Time is a thief. } \\
\text { Found sentence: } & \text { If time is a thief of memory, I've been royally } \\
& \text { fleeced. }
\end{array}
$$

The produced sentence still refers to time as a thief; however, the addition of the prepositional phrase of memory restricts the meaning of thief in a way not relevant to the target sentence.

\section{Constraints for the Explanations}

Constraint 8: The principle of no repetition. Each explanation is counted once. Therefore, the number of explanations for a figurative claim is the number of different explanations found for the figurative claim. See also Constraint 6 .

Constraint 9: Elaboration rather than explanation. Some productions are elaborations of the metaphor or simile, not explanations. Their relative clauses are introduced by conjunctions other than because, and when replaced by the conjunction because they become ungrammatical. For example: Time is like a thief that steals everything away. This is ungrammatical written as time is like a thief [because] steals everything away. A legitimate explanation is Music is like medicine, as it takes away the pain. This is grammatical written as Music is like medicine because it takes away the pain.

Fifty-two topic-vehicle pairs used by Chiappe, Kennedy, and Chiappe (2003) were entered into Google. Only 26 of these pairs, however, had corresponding productions on Google. A further 13 topic-vehicle pairs were removed from the analysis because there were fewer than nine productions of metaphors and similes combined.

Using the constraints listed above, each production was judged for legitimacy. The productions and contexts were recorded and examined by all three authors independently, and only instances judged unanimously to be legitimate were kept. The final list of pairs of terms is in Table 1.

Because Google often produced a large number of instances of a particular topic-vehicle pair, only the first 30 legitimate productions of each metaphor and simile were retained if the number of productions exceeded 60 . Otherwise, all productions of the target sentence were examined.

\section{Results}

The mean proportion of metaphors with explanations was $.06(S D=.07)$; of similes, $.31(S D=.26), z=8.6$, $p<.01$. For metaphors, proportions ranged from 0 for alcohol is a crutch, cities are jungles, lawyers are sharks, life is a journey, and time is money to .23 for music is medicine. For similes, proportions ranged from 0 for alcohol is like a crutch, cities are like jungles, and soldiers are like pawns to .73 for time is like money. In total, .79 of all explanations occurred with a simile (see Table 1).

The results were promising. However, the topic-vehicle pairs from Chiappe, Kennedy, and Chiappe (2003) were obtained from the psychological literature on metaphor, and the search was with these preselected pairs. Comparisons that are found with a less-specific search would strengthen the claim. Also, only 13 topic--vehicle pairs were compared in Experiment 1. Additional comparisons would be useful.

\section{EXPERIMENT 2}

\section{Method}

Statements to do with the terms "metaphor" and "simile" were searched for on the Internet using Google. Four search phrases were employed: "common metaphor," "common simile," "an example of a metaphor is," and "an example of a simile is." The same criteria as in

Table 1

Metaphors and Similes in Experiment 1, Frequency of Explanations

\begin{tabular}{lccccc}
\hline & \multicolumn{2}{c}{ Metaphors } & & \multicolumn{2}{c}{ Similes } \\
\cline { 2 - 3 } \cline { 5 - 6 } \multicolumn{1}{c}{ Pairs } & $\begin{array}{c}\text { With } \\
\text { Explanation }\end{array}$ & $\begin{array}{c}\text { Without } \\
\text { Explanation }\end{array}$ & & $\begin{array}{c}\text { With } \\
\text { Explanation }\end{array}$ & $\begin{array}{c}\text { Without } \\
\text { Explanation }\end{array}$ \\
\hline Alcohol-crutch & 0 & 15 & & 0 & 0 \\
Cities-jungles & 0 & 7 & & 0 & 1 \\
Crime-disease & 3 & 27 & & 2 & 3 \\
Genes-blueprints & 1 & 35 & & 3 & 3 \\
Lawyers-sharks & 0 & 24 & & 2 & 4 \\
Life-journey & 0 & 30 & & 5 & 25 \\
Love-drug & 2 & 28 & & 19 & 11 \\
Minds-computers & 2 & 22 & & 23 & 19 \\
Music-medicine & 7 & 23 & & 7 & 21 \\
Soldiers-pawns & 1 & 19 & & 0 & 1 \\
Time-money & 0 & 30 & & 21 & 32 \\
Time-thief & 5 & 24 & & 1 & 1 \\
Words-daggers & 1 & 24 & & 1 & \\
\hline
\end{tabular}


Experiment 1 were used to deem examples to be relevant, but without the no-example constraint, and with one additional constraint:

Constraint 10: No synonym. An explanation was rejected if it simply replaced the vehicle with a synonym, for example, God is a rock, that is to say, a stone.

\section{Results}

The mean proportion of metaphors having explanations was .03; of similes, .31, $(z=10.17, p<.01)$. For metaphors, proportions ranged from 0 to .06; for similes, from 0 to .56 (love is like a rose); see Table 2. Also, though only .31 of similes were accompanied by explanations, .86 of the explanations were preceded by a simile (very much in accord with the result of .79 in Experiment 1).

\section{Discussion}

Metaphors often appear in Internet text without explanation. It would seem that their writers deem them relatively intelligible. More frequently, similes carry explanations. Seemingly, readers may be quite likely to require aid in understanding them.

One factor could be the expression's aptness. Metaphor is favored if the relevant features that the topic and vehicle share are highly significant in understanding the topic; that is, they are apt. Crime is a disease points out that contagion and decay are relevant, for example. Education is a stairway makes progress relevant. Cities are jungles argues that danger and lack of control are relevant. Life is a joke suggests that we are the butt.

In addition, writers may use metaphors when the key features are expected to come to mind without prompting (Gentner \& Bowdle, 2001). Love is a devil alerts us to love's perils. Heaven is a treasure emphasizes heaven's value. If the topic and vehicle do not share a set of relevant and salient features (Giora, 2003), then interpretation is not easy. The topic and vehicle have many features to consider. Several interpretations might be possible. Of impor- tance, the intended features may be so low in salience that the unaided reader would never consider them.

No explanations were added to time is money as a metaphor. Its salient meaning is, "our time on the job costs someone money." The implication is that our time is valuable and is not to be wasted.

Several expressions, including time is money, Christians are salt, and love is a rainbow, were given no explanations as metaphors and a large number as similes. Surely this means that the metaphor version of the timemoney pair, for example, may have a specific meaning (Gibson, 1979), but the simile version is given creative or far-fetched accounts, abetted by explanations. Time is like money, a simile, was given explanations such as the less we have of it to spare, the further we make it go and once it's spent, it's gone. Accompanied by explanations, this expression specifies less salient aspects of money. It can refer to scarcity, investment, or running out of money, for example.

The stock-in-trade of similes is what the prompting explanation can bring readily to mind. In effect, similes, via explanations, can license adroit narrow applications such as time is like money-only retired executives have a lot. A more upbeat example might be time is like money and you can invest yours in your education. This account can explain why similes are often used in riddles (as in why is a raven like a writing desk?), licensing highly specific referents (because Poe wrote on both) based on common features with a clever, unexpected, humorous side (playing on two meanings of $o n$ ).

Less apt expressions that subjects reject as metaphors can be rescued by expressing them as similes plus an explanation. A canary is a wolf might be rejected, but readers may suspend judgment on a canary is like a wolf, looking for a justification in the text. It might be that flocks of canaries in competition for territory in their natural habitat are unrelentingly vicious to some other birds.

Table 2

Metaphors and Similes in Experiment 2, Frequency of Explanations

\begin{tabular}{|c|c|c|c|c|}
\hline \multirow[b]{2}{*}{ Pairs } & \multicolumn{2}{|c|}{ Metaphors } & \multicolumn{2}{|c|}{ Similes } \\
\hline & $\begin{array}{c}\text { With } \\
\text { Explanation }\end{array}$ & $\begin{array}{c}\text { Without } \\
\text { Explanation }\end{array}$ & $\begin{array}{c}\text { With } \\
\text { Explanation }\end{array}$ & $\begin{array}{c}\text { Without } \\
\text { Explanation }\end{array}$ \\
\hline Bible-sword & 0 & 18 & 3 & 5 \\
\hline Christ-door & 0 & 10 & 1 & 1 \\
\hline Christian-salt & 0 & 16 & 7 & 7 \\
\hline God-fire & 0 & 30 & 5 & 11 \\
\hline God-rock & 3 & 27 & 6 & 24 \\
\hline Hair-rainbow & 0 & 8 & 0 & 5 \\
\hline Heaven-treasure & 1 & 16 & 2 & 4 \\
\hline Life-joke & 0 & 30 & 7 & 23 \\
\hline Life-river & 1 & 29 & 7 & 23 \\
\hline Love-devil & 0 & 16 & 2 & 3 \\
\hline Love-flower & 1 & 29 & 11 & 19 \\
\hline Love-gold & 3 & 27 & 11 & 19 \\
\hline Love-melody & 1 & 22 & 0 & 16 \\
\hline Love-oxygen & 2 & 23 & 7 & 16 \\
\hline Love-rainbow & 0 & 30 & 10 & 20 \\
\hline Love-rose & 3 & 27 & 17 & 13 \\
\hline Man-island & 0 & 30 & 1 & 1 \\
\hline TV-drug & 2 & 28 & 7 & 15 \\
\hline
\end{tabular}




\section{Conventionality}

Conventionality plays such a significant role in figurative language that highly conventional expressions have their own classification - cliché. Gentner and Bowdle (2001) pointed out that the vehicles of many metaphors are highly conventional; for example, schools are a jungle uses jungle in the same way as does cities are a jungle. They argued that one result may be that we use a simile to express an unfamiliar comparison and a metaphor for a familiar one. Interestingly, however, explanation proportions on Google were strongly correlated $(r=+.70$, $p<.001$ ) with the conventionality ratings of the vehicle provided by Chiappe, Kennedy, and Chiappe (2003). For example, thief, computers, and blueprints are ranked first, second, and third in terms of vehicle conventionality in Chiappe, Kennedy, and Chiappe, and all three have simile explanation ratings higher than .49 . That is, despite their high conventionality, they are used as similes (albeit adorned with explanations), precisely the reverse of what one might predict at first blush. Instructively, what this suggests is that highly conventional vehicles are often qualified and repurposed! If minds are computers does not spotlight the features the writer wants, the writer specifies them explicitly. For example, Internet explanations redirected it with: in that brains are like hardware and minds are like software; with as all information is stored there; with what we put in is what we get out; and with garbage in, garbage out.

\section{Internet Productions}

Chiappe, Kennedy, and Chiappe (2003) examined preference for expressing a comparison between two terms as a metaphor or as a simile. We correlated their metaphor preference ratings for a given pair with the proportion of metaphors to similes for that pair found by Google in Experiment 1. The 52 topic-vehicle pairs from Chiappe, Kennedy, and Chiappe were considered. We rejected pairs that had 3 or fewer productions (metaphors and similes combined), leaving 21 pairs. We recorded all legitimate productions for the remaining topic-vehicle pairs (not only the first 30 ). The Google proportions correlated with the Chiappe, Kennedy, and Chiappe metaphor preferences $(r=+.57, p<.001)$. Evidently, preferences expressed in an experimental context predict widespread use.

One might wonder whether our results reflect written language but not spoken language. This question is worth further examination. However, we note that messages on the Internet are often closer in form to actual speech than are academic papers and published works. They include nonlexicalized sounds (e.g., that is waaaaaay too harsh, I SO disagree), and often include nonstandard syntax (e.g., you wanna go?).
Internet search methods obtain information easily and reliably. The positive correlation between preferences in Chiappe, Kennedy, and Chiappe (2003) and Google's productions suggests that results can be generalized validly, paving a way for Internet tests of other language theories. The close fit between the results of Experiments 1 and 2 suggests that results obtained by different methods of searching the Internet reinforce each other.

We used the same word pairs in our searches and comparisons. This was to control for content. An interesting possibility is that some word pairs may occur only as similes or only as metaphors. An example is riddles, which overwhelmingly occur as similes. Another example is clichéd metaphors, such as God is love. These fell outside of our constraints. We conjecture that the riddles are far fetched, and require explanation, and that the clichés have passed beyond an extreme measure of conventionalization, are often taken to be literal claims of fact, and are rarely followed by explanation. Another conjecture is that a sentence-by-sentence search of texts (or records of speech) for, say, 1,000 metaphors and 1,000 entirely unrelated similes, should find explanations more frequent for similes.

We searched for explanatory text following a word pair. However, text preparing the way for metaphors and similes with different levels of explanatory transparency may mirror the subsequent text. It may be terse before an apt metaphor that has no trailing explanation, and especially expository before a simile that has one.

We conclude that our Internet study of metaphors and similes finds similes more often supplemented by explanations. Notably, similes are favored if a standard vehicle's use has to be qualified.

\section{REFERENCES}

Chiappe, D. L., \& Kennedy, J. M. (1999). Aptness predicts preference for metaphors or similes, as well as recall bias. Psychonomic Bulletin \& Review, 6, 668-676.

Chiappe, D. L., Kennedy, J. M., \& Chiappe, P. (2003). Aptness is more important than comprehensibility in preference for metaphors and similes. Poetics, 31, 51-68.

Chiappe, D. [L.], Kennedy, J. M., \& Smykowski, T. (2003). Reversibility, aptness, and the conventionality of metaphors and similes. Metaphor \& Symbol, 18, 85-105.

Gentner, D., \& Bowdle, B. F. (2001). Convention, form, and figurative language processing. Metaphor \& Symbol, 16, 223-247.

GiBson, J. J. (1979). The ecological approach to visual perception. Boston: Houghton Mifflin.

Giora, R. (2003). On our mind: Salience, context, and figurative language. Oxford: Oxford University Press.

GLUCKSBERG, S. (2001). Understanding figurative language: From metaphors to idioms. Oxford: Oxford University Press.

(Manuscript received July 13, 2004; revision accepted for publication June 17, 2005.) 